\title{
Genetic Effects on Stillbirth and Calving Difficulty in Swedish Holsteins at First and Second Calving
}

\author{
L. Steinbock*, A. Näsholm*, B. Berglund*, K. Johansson† and J. Philipsson* \\ *Department of Animal Breeding and Genetics, \\ Swedish University of Agricultural Sciences \\ SE-750 07 Uppsala, Sweden \\ †Swedish Dairy Association, SE-631 84 Eskilstuna, Sweden
}

\begin{abstract}
In Swedish Holstein dairy cattle, genetic effects on stillbirth and calving difficulty were studied in 411,409 first- and 281,193 second-calvers. A linear single-trait sire-maternal grandsire model and a threshold model using a Gibbs sampling technique were used to analyse calving data from 1985 to 1996 . In first calving when using the linear model, the heritability of stillbirth on the visible scale was $4 \%$ for the direct effect and $3 \%$ for the maternal effect. For calving difficulty it was $6 \%$ and $5 \%$ for direct and maternal effects, respectively. In second calving the corresponding heritabilities for the two traits were considerably lower, less than $1 \%$. Adjusting for calving difficulty in linear analysis of stillbirth halved the heritabilities for the direct and maternal effects in first calving. When using a threshold model, heritabilities for stillbirth in first-calvers were $12 \%$ and $8 \%$ for direct and maternal effects, respectively, and for calving difficulty they were $17 \%$ and $12 \%$. At second calving corresponding heritabilities were 2 to $4 \%$ for stillbirth and 4 to $7 \%$ for calving difficulty. The correlation between direct and maternal effects was around -0.1 , irrespective of whether the linear or the threshold model was used for first-calvers. The genetic correlations between bulls' EBV from first and second calving were 0.4 to 0.5 for direct and maternal effects in stillbirth, whereas they were 0.6 to 0.7 for calving difficulty. In first-calvers there was a substantial genetic variation in both traits, expressed by differences between breeding values of bulls, despite fairly low heritability. The results obtained in this study suggest that first-parity records should preferably be used for genetic evaluation of bulls for calving performance. In such routine evaluations both stillbirth and calving difficulty, and both direct and maternal effects, should be included.
\end{abstract}

Received March 27, 2002.

Accepted November 27, 2002.

Corresponding author: L. Steinbock; e-mail: lena.steinbock@hgen. slu.se.
(Key words: stillbirth and calving difficulty, direct and maternal genetic effects, threshold model)

Abbreviation key: SLB = Swedish Holstein, HF = Holstein Friesian, REML = restricted maximum likelihood.

\section{INTRODUCTION}

The stillbirth rate in Swedish Holstein (SLB) heifers has increased over the past 10 to $15 \mathrm{yr}$. During the same time period the import of semen Holstein Friesian (HF) from North America has increased and the proportion of HF-genes in the population has increased dramatically and thus the breed has gradually transformed from the Swedish Friesian into $\mathrm{HF}$ and the breed is therefore now called Swedish Holstein. At first calving around $10 \%$ of the calves are born dead or die on the first day. This figure is almost twice as high as for Swedish Red and White at first calving A considerable difference exists between heifers and multiparous cows, the stillbirth rate being around $4 \%$ for older SLB cows. For older cows breed differences in stillbirth rate seem nonexistent (Swedish Dairy Association, 2000). In other countries the stillbirth rate is also considerable. For instance, it increased in the U.S. from $9.5 \%$ in 1985 to 13.2\% in 1996 for first calving Holsteins (Meyer et al., 2001), while in The Netherlands the stillbirth rate for first-calvers was reported to be $12.2 \%$ in 1999 (Harbers et al., 2000).

Stillbirths and calving difficulties are influenced by both direct and maternal genetic effects, i.e. the genetic constitution of both the sire and maternal grandsire has an impact on the birth process and its outcome. In the Holstein population, large variation in stillbirth rates among bulls as sires and as maternal grandsires, ranging between 2 and $25 \%$, has been observed in large progeny groups (Berglund and Philipsson, 1992; Philipsson et al., 1997). Stillbirth problems appear to be rather different today, compared with earlier experience, as stillbirths seem to be less closely related to high birth weight and to difficult calving than they used to be (Berglund and Philipsson, 1992; Steinbock et al., 
1997). Nowadays, among SLB heifers, more than half of all stillborn calves are born at normal or easy calvings (Berglund, 1996; Steinbock et al., 1997).

A wide variation is obviously present in stillbirth rate at first calving (Berglund 1996; Philipsson et al.,1997). The questions are: to what extent is there genetic variation in stillbirth rate independent of calving difficulty, and is there any important genetic variation in second calvers? The objectives of this study were therefore to estimate genetic parameters for direct and maternal effects for both stillbirth rate and calving difficulty for first- and second-calvers separately, and to estimate the genetic correlation between the traits of the two parities. This information is needed both to define traits for the selection of bulls, and to optimize breeding programs designed to minimize calving difficulties and stillbirths.

\section{MATERIALS AND METHODS}

\section{Data Structure}

Records on Holstein calves born between 1985 and 1996 were obtained from the official Swedish milk-recording scheme. Data from first- and second-calvers were used. Analyses were carried out using data that were restricted to single calvings, heifers whose age at first calving was in the range 20 to 38 mo, gestation duration between 256 and $304 \mathrm{~d}$, and records with information on both sire and maternal grandsire of calf. Where the sex of a stillborn calf was not recorded, it was randomly computed with the assumption that $60 \%$ of all stillborn calves are males (Philipsson, 1976a). Table 1 shows the structure of the edited data, together with incidences of stillbirth and calving difficulty.

Stillbirth was defined as a calf dead at birth, or that died within $24 \mathrm{hr}$ of birth. Calving difficulty was defined as a calving where the heifer/cow needed assistance by more than one person, or when there was malpresentation of the calf. Malpresentation is one of the options for the herdsmen to chose when describing the calving performance and it was treated as a difficult calving.

\section{Statistical Methods}

In first-calvers, variance and covariance components were estimated for the two traits using the single-trait sire-maternal grandsire model;

$$
\begin{aligned}
Y_{\mathrm{ijk} l m n o p q}= & \mu+a_{\mathrm{i}}+b_{\mathrm{j}}+c_{\mathrm{k}}+d_{1}+f_{\mathrm{m}}+s_{\mathrm{ln}} \\
& +m g s_{\mathrm{mo}}+h y_{\mathrm{p}}+e_{\mathrm{ijk} l m n o p q}
\end{aligned}
$$

where
$Y_{\text {ijklmnopq }}$ denotes a 0 or 1 for live vs. stillborn and easy/normal vs. difficult calving,

$\mu=$ the overall mean,

$a_{\mathrm{i}}=$ fixed effect of the $i$ th combination of heifer's calving age in months and sex of calf, $b_{\mathrm{j}}=$ fixed effect of $j$ th year of calving,

$c_{\mathrm{k}}=$ fixed effect of $k$ th season of calving,

$d_{1}=$ fixed effect of $l$ th genetic group of sire of calf,

$f_{\mathrm{m}}=$ fixed effect of $m$ th genetic group of calf's maternal grandsire,

$s_{\mathrm{ln}}=$ random effect of calf's sire,

$m g s_{\mathrm{mo}}=$ random effect of calf's maternal grandsire,

$h y_{\mathrm{p}}=$ random effect of herd $\times$ year, and

$e_{\mathrm{ijklmnopq}}=$ random residual effect.

In the analysis of second-calvers the combination of age of heifer and sex of calf was replaced by the effect of sex of calf only.

Heifers' ages were divided into seven classes: 20 to 22,23 to 24,25 to 26,27 to 28,29 to 31,32 to 34 and 35 to $38 \mathrm{mo}$ at calving. Calving seasons were divided into five classes, due to the Swedish calving season, which begins in August, and due to the grazing periods. The classes were: late grazing period, August through September; fall, October; winter, November through February; spring, March through April; and early grazing period, May through July. The sires were distributed into 124 and 111 groups in first and second calving, respectively, and maternal grandsires were distributed into 130 and 112 groups in first and second calving, respectively. The groups were based on bull's year of birth and on the proportion of HF-genes, expressed in quartiles, and was done in order to express the genetic difference between bulls due to the gradual Holsteinization present in the population. If there were fewer than 5 bulls in any group, the groups were assembled by year of birth only. Herd $\times$ year combinations with fewer than five calvings were put together in one group per herd over years.

Sire of sire and maternal grandsire as well as maternal grandsire of sire and maternal grandsire were included in the relationship matrix.

The analysis for stillbirth was also run with calving difficulty included as a fixed effect for both first- and second-calvers in order to explain the dependence of the genetic variation in stillbirth on calving difficulty. A bivariate analysis using the model described above was also made in order to obtain the genetic correlation between stillbirth and calving difficulty.

The calving performance traits were analysed with both linear mixed models and threshold models. Variance components from the linear mixed models were estimated using a restricted maximum likelihood 
(REML) procedure (Jensen and Madsen, 1994). In a Bayesian analysis, inference from a threshold model was based on a posterior distribution achieved with Gibbs sampling technique (Jensen, 1994). In the threshold model, the occurrence of a stillbirth or a difficult calving was assumed to be the result of a normally distributed variate - a liability value. The liability values for stillbirth were created by data augmentation, as described by Sørensen (1996), using random normal deviates from distributions conditional on the other effects in the model. The environmental variance was assumed to be 1 and the threshold was set to 0 .

Uniform, improper prior distributions were used for fixed effects. Vague priors for variance components were calculated for calving difficulty from Ducrocq (2000). They were also used as prior information in the analysis on stillbirth as (co)variances on stillbirth were not found in the literature. To test the sensitivity to prior information the data was also analysed using information calculated from the linear analysis. There were however no important differences in the results between the two sets of prior information. A chain of 11,000 samples for first-calvers was used and 14,000 samples for second-calvers. The first 300 samples were regarded as burn-in period and discarded. The effective number of independent observations and lag correlations were calculated as described by Sorensen et al. (1995).

The expectations of the estimated variances, covariances are given by Kriese et al. (1991) and were calculated together with the heritabilities for the direct and maternal effects as:

$$
\begin{aligned}
\sigma_{\text {dir }}^{2} & =4 \sigma_{s}^{2} \\
\sigma_{\text {dir-mat }} & =4 \sigma_{s-m g s}-1 / 2 \sigma_{d i r}^{2} \\
\sigma_{\text {mat }}^{2} & =4 \sigma_{m g s}^{2}-1 / 4 \sigma_{d i r}^{2}-\sigma_{d i r-m a t} \\
\sigma_{p}^{2} & =\sigma_{s}^{2}+\sigma_{m g s}^{2}+\sigma_{e}^{2} \\
\mathrm{~h}_{\text {dir }}^{2} & =4 \sigma_{s}^{2} / \sigma_{p}^{2} \\
\mathrm{~h}_{\text {mat }}^{2} & =4 \sigma_{\text {mat }}^{2} / \sigma_{p}^{2}
\end{aligned}
$$

The genetic correlation between direct and maternal effects was calculated as:

$$
\mathrm{r}_{\mathrm{g}_{\text {dir-mat }}}=\sigma_{\text {dir-mat }} / \sqrt{\sigma_{d i r}^{2} \sigma_{m a t}^{2}}
$$

where the subscripts dir and mat represent direct and maternal additive effects, respectively. Variances and covariances with appropriate subscripts of maternal grandsires and sires were taken from the output of the REML procedure and Gibbs sampling, respectively. Monte Carlo standard errors of the posterior means and effective number of independent observations were calculated as described by Sorensen et al. (1995). For first-calvers, the Gibbs chain reached equilibrium distribution almost immediately. For the second-calvers, the chain was less stable, but also seemed to have reached equilibrium distribution relatively early.

For purposes of comparison, heritabilities from the linear analyses were transformed to the underlying scale according to Dempster and Lerner (1950).

EBV from linear analyses were used to calculate correlations between results for bulls represented with at least 100 offspring as sires and maternal grandsires, respectively, in first and second calving. The method proposed by Calo et al. (1973) was used to adjust the calculated correlations to genetic correlations.

The ETA for bulls as sires and maternal grandsires were presented as percentage of stillbirths and difficult calvings respectively and the range in values among bulls was calculated by adding the population means from Table 1.

\section{RESULTS}

Table 1 presents the incidence levels for stillbirth and calving difficulty for first- and second-calvers as an average over the period studied. The incidences were much higher in first calving for both traits. The incidence of neither stillbirth nor calving difficulty in second calving changed particularly over the $10 \mathrm{yr}$ studied, whereas in first calving there was a large increase in stillbirth rate, from below $6 \%$ in 1985 to almost $9 \%$ at the end of the period.

Age of the heifer at calving in connection with sex of calf had a considerable impact on calving performance (Figure 1). For bull calves there was a considerable difference in stillbirth rate between young and old

Table 1. Incidences (\%) of stillbirth, calving difficulty and proportion of dead calves at normal calvings and numbers of sires and maternal grandsires (mgs) of calves.

\begin{tabular}{lllllllll}
\hline & & \multicolumn{4}{c}{ Incidence } & & No. of bulls being & \\
Parity & $\begin{array}{l}\text { No. of } \\
\text { records }\end{array}$ & Stillbirths & $\begin{array}{l}\text { Calving } \\
\text { difficulties }\end{array}$ & $\begin{array}{l}\text { Dead calves at } \\
\text { normal calvings }\end{array}$ & sires & mgs & & $\begin{array}{l}\text { Total no. } \\
\text { of bulls }\end{array}$ \\
\hline 1 & 411,409 & 7.1 & 8.3 & 53 & 2362 & 2468 & 2955 \\
2 & 281,193 & 2.7 & 4.5 & 33 & 806 & 1681 & 1905 \\
\hline
\end{tabular}




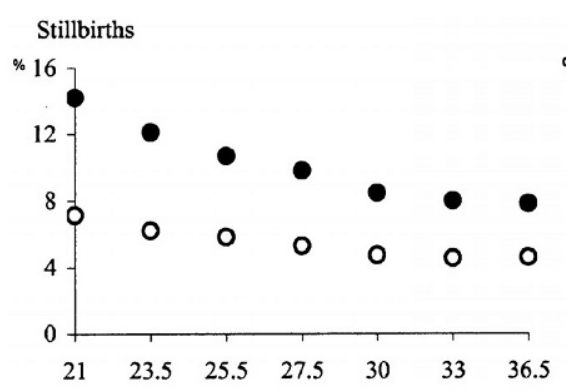

Months
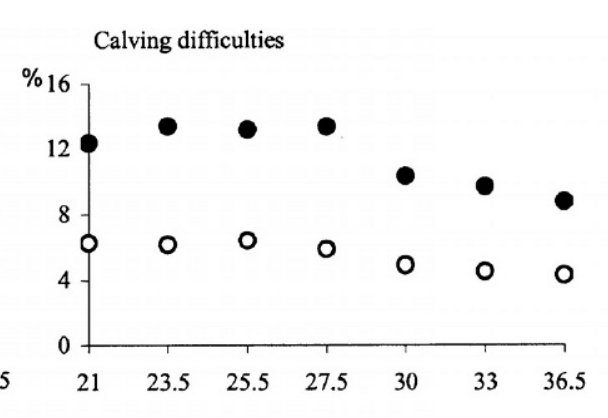

Months

Figure 1. Incidences of stillbirths and calving difficulties in different calving ages of heifers. The illustrated figures are the average age (mo) in each class.

dams, whereas it was 10 to $14 \%$ up to the age of 26 mo, it decreased to $8 \%$ at the higher ages. Although stillbirth rates for heifer calves were not as high, the trend was similar to but less pronounced than for bull calves. Regarding calving difficulty, there was an appreciable difference between bull and heifer calves, but there did not seem to be the same distinct connection with age. However, the older heifers, 30 mo of age and above, did not have as much calving difficulty as the younger ones.

The rate of difficult calving in heifers increased appreciably from October to, March and April where the peak was (Figure 2). In the summer months (May to September), when the heifers are out at pasture, the incidence of difficult calving was lowest. The stillbirth rate closely followed the same trend as the incidence of calving difficulty except that it was only low in late summer and early autumn.

In Figure 3 the sires and maternal grandsires of the calves from heifers are divided into five genetic groups in order to show how the proportion of HF-genes affects

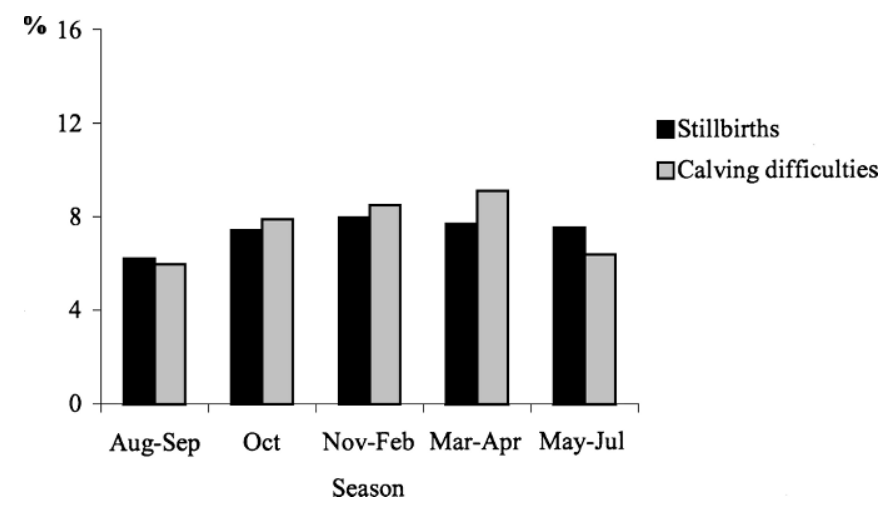

Figure 2. Effects of season of calving on stillbirths and calving difficulties at first calving. the rate of stillbirth and calving difficulty, respectively. For stillbirth, sires with $50 \%$ or more HF-genes gave a higher stillbirth rate than the average $7.1 \%$ in all data. For maternal grandsires, only the bulls without HFgenes gave a stillbirth rate above average of $10.1 \%$. For calving difficulty, the sires without HF-genes gave almost no difficulty at all. For the pure HF-sires too, the rate was below the average of $8.4 \%$. Most calving difficulty was caused by sires with $50 \%$ HF-genes (14.3\%). Also for maternal grandsires the highest rate of calving difficulty was reached by those with $50 \%$ HFgenes; the others had rates on or slightly below average.

Genetic parameters estimated in univariate analyses are presented in Tables 2 and 3. On the visible scale for first calving, heritabilities for stillbirth were $3.8 \%$ and $2.8 \%$ for direct and maternal effects, respectively. For calving difficulty the corresponding values were $6.2 \%$ and $4.8 \%$. In second calving the heritabilities were very low-between $5 \%$ and $20 \%$ of the estimates from first calving.

When heritabilities estimated on the visible scale were transformed to the underlying scale, the difference between parities was not so great. The estimates were still at most $30 \%$ of the values from first calving. Threshold model heritability estimates in first-calvers were: for stillbirth, $12 \%$ and $8 \%$, and for calving difficulty, $17 \%$ and $12 \%$ for direct and maternal effects, respectively. For both traits in first calving, the heritabilities were similar to the transformed linear ones. In second-calvers the threshold model estimates were the same as the transformed ones for stillbirth (4\% and $2 \%$ for direct and maternal effects). For calving difficulty, however, the threshold model heritability estimates were higher than the transformed ones, $7 \%$ compared with $2 \%$ for the direct effect and $4 \%$ compared with $1 \%$ for the maternal effect. The genetic correlations between direct and maternal effects were rather low and negative for stillbirth at both calvings, and for calv- 

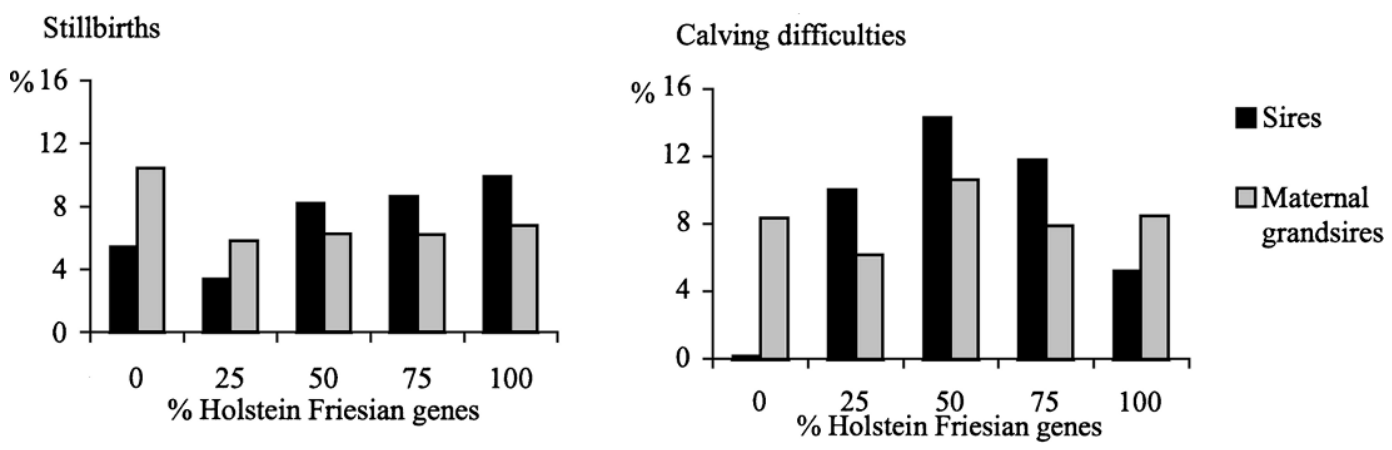

Figure 3. Average effect of proportion of Holstein Friesian genes on calving traits at first calving for bulls as sires and maternal grandsires of the calves.

ing difficulty in first calving. The threshold model gave results very similar to those of the linear method.

When adjusting for calving difficulties in the model, heritabilities for stillbirth decreased to about half the values, without adjustment (Table 3 ).

Genetic correlations between stillbirth rate and calving difficulty were 0.80 for the direct effects and 0.74 for the maternal effects in first-calvers (not shown in a table). The other estimates of direct and maternal heritabilities, and direct-maternal genetic correlations, derived from the bivariate analyses were very close to the estimates derived from the single-trait linear analyses and are therefore not presented in detail.

The correlations between EBV for bulls in first and second calving, and the calculated corresponding ge-
Table 3. Genetic parameters for stillbirth adjusted for calving difficulty estimated from a linear model on the visible scale and transformed to underlying scale.

\begin{tabular}{llll}
\hline & & \multicolumn{2}{c}{ Linear analysis } \\
\cline { 3 - 4 } & Parity & $\begin{array}{l}\text { Visible } \\
\text { Scale }\end{array}$ & $\begin{array}{l}\text { Underlying } \\
\text { Scale }\end{array}$ \\
\hline $\mathrm{h}_{\text {direct }}^{2} \%$ & 1 & 2.0 & 7 \\
$\mathrm{~h}_{\text {maternal }}^{2} \%$ & 2 & 0.3 & 2 \\
& 1 & 1.0 & 5 \\
$\mathrm{r}_{\mathrm{g} \text { direct-maternal }}$ & 2 & 0.1 & 1 \\
& 1 & -0.16 & \\
\hline
\end{tabular}

netic correlations, are presented in Table 4. For still-

Table 2. Genetic parameters for stillbirth and calving difficulty estimated in linear REML analysis (values on visible scale and transformed to underlying scale) and in threshold analysis.

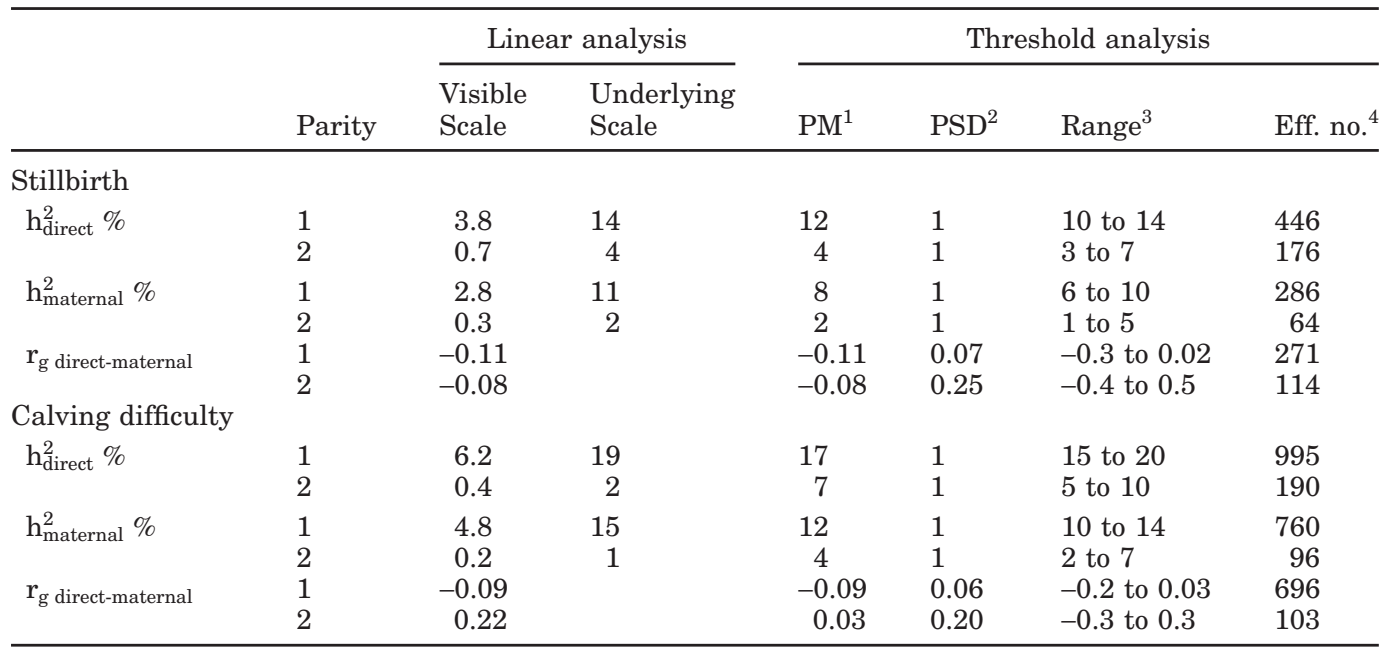

${ }^{1}$ Posterior mean.

${ }^{2}$ Posterior standard deviation.

${ }^{3}$ Range of posterior distribution after deleting $2.5 \%$ of the highest and lowest values, respectively.

${ }^{4}$ Effective numbers of independent observations from the marginal posterior distributions. 
birth, the genetic correlations for both the direct and maternal effects were 0.4 to 0.5 ; for calving difficulty they were slightly higher: 0.6 to 0.7 .

Table 5 shows the range in ETA for bulls. The difference between bulls both as sires and as maternal grandsires of the calves is considerable for both calving traits in heifers. In second calving, where the incidences were considerably lower, the range between bulls is much smaller.

\section{DISCUSSION}

\section{Method for Analysis}

With the exception of the heritability estimates for calving difficulty in second-calvers, there was a great similarity between the heritabilities derived from the threshold model and the transformed heritabilities from the linear model. Thus, the transformation of the heritabilities worked quite well with these data despite the low incidence levels. The estimated posterior distributions were considered normal, except for the maternal heritability distribution of stillbirth in second calving. These were skewed, with a tail to the right, an effect of the proximity of the posterior mean to zero. Due to the smaller number of observations, and to the lower incidence levels found in second-calvers, the posterior distributions were wider and it was more difficult to disentangle direct from maternal effects. Consequently the lag correlations were larger in secondcalvers and the effective number of independent samples was lower. The posterior distributions for the estimated genetic correlations in second calving were also very wide and their ranges were more or less centered around zero.

\section{Heritabilities}

The estimates of heritabilities for stillbirth rate at first calving obtained from linear analyses have almost doubled, compared with previous Swedish results (Philipsson, 1976b). This is partly an effect of the increased incidence level. For calving difficulty, however, the heritabilities were lower than in the earlier study, which was probably based on more accurate recording, being an experimental field study. The heritabilities estimated for second calving were less than a third of the values for first-calvers when the threshold model was used, and, as could be expected, were even lower when estimated on the visible scale.

The increased genetic variation in stillbirth is probably an effect of the ongoing "holsteinization" during the period under study. An association between a higher proportion of HF-genes and increased stillbirth rate was found in our earlier study (Berglund and Philipsson, 1992). When bulls were sires of calves there was an obvious connection between the proportion of HFgenes and the higher incidence of calving difficulty and stillbirth, whereas the maternal effects show no obvious pattern. However, the results are difficult to interpret due to the time-lag between the generations of bulls with similar HF levels as sires and maternal grandsires, and their expression of direct and maternal genetic effects including the covariance between these.

The adjustment of stillbirth for calving difficulty in the model caused at both calvings a reduction of the heritability to about half compared with no adjustment. Thus, the genetic variation in stillbirth rate is partly independent of the incidence of calving difficulty. This is supported by the genetic correlations between stillbirth and calving difficulty as direct (0.80) and maternal effects (0.74) in heifers.

\section{Correlations Between Parities}

Genetic correlations between results for bulls with records from first and second calvings were of moderate size for both traits (Table 4). Between 20 and 50\% of the genetic variation is common to both parities. For Holsteins in The Netherlands, the genetic correlations for direct and maternal effects between first and second calving were 0.52 and 0.78 , respectively, for stillbirth (Harbers et al., 2000). In the U. S. Holstein population it was found that stillbirths at first and second calving

Table 4. Correlations between estimated breeding values from first- and second-calvers for stillbirth and calving difficulty in bulls with at least 100 offspring as sires and maternal grandsires, respectively.

\begin{tabular}{llll}
\hline & $\begin{array}{l}\text { Correlation } \\
\text { between EBV }\end{array}$ & $\begin{array}{l}\text { Genetic } \\
\text { correlation }^{1}\end{array}$ & $\begin{array}{l}\text { Number } \\
\text { of bulls }\end{array}$ \\
\hline $\begin{array}{l}\text { Stillbirth } \\
\quad \text { Sires }\end{array}$ & 0.23 & & \\
$\quad$ Maternal grandsires & 0.31 & 0.45 & 440 \\
$\begin{array}{l}\text { Calving difficulty } \\
\quad \text { Sires }\end{array}$ & 0.26 & 0.48 & 471 \\
$\quad$ Maternal grandsires & 0.41 & 0.61 & 440 \\
\hline
\end{tabular}

${ }^{1}$ Calculated according to Calo et al., (1973). 
Table 5. Range in estimated transmitting abilities for stillbirth and calving difficulty in bulls as sires and maternal grandsires, respectively, with at least 100 offspring.

\begin{tabular}{llll}
\hline Trait & Parity & Sires & Maternal grandsires \\
\hline Stillbirth, \% & 1 & 2.8 to 16.0 & 3.4 to 13.7 \\
Calving difficulty, \% & 2 & 0.8 to 4.3 & 2.0 to 3.6 \\
& 1 & 1.6 to 16.7 & 4.1 to 15.1 \\
& 2 & 2.6 to 6.1 & 3.1 to 5.7 \\
\hline
\end{tabular}

should be regarded as different traits and analysed separately (Meyer et al., 2000). Despite the medium-high correlations, the low incidence and heritability values at second calving mean that these records would not contribute much to the accuracy in estimation of breeding value of bulls for stillbirth and calving difficulty. The genetic contribution to a visible variation in stillbirth and calving difficulty in second-calvers is rather small, as is obvious from the variation shown in ETA among bulls in Table 5 .

Ducrocq (2000) estimated correlations between EBV of bulls for calving difficulties between heifers and older cows and obtained clearly higher estimates $(0.8$ and 0.7 for sires and maternal grandsires, respectively) than ours for both the direct and the maternal effects. Ducrocq (2002) got a higher estimate for the direct effect, the complete opposite of the result in our study. The heritabilities estimated on the underlying scale in that study were much lower, though, than those obtained in our study. The differences in heritabilities between first- and second-calvers was not as marked as in our study, although the incidences of difficult calvings were $9.6 \%$ and $3.3 \%$ in first- and second-calvers, respectively.

\section{Correlations Between Traits}

The small but consistent antagonistic genetic correlations that were found to exist between the direct and maternal effects in first-calvers, for stillbirth and for calving difficulty, indicate the need to evaluate bulls both as sires and as maternal grandsires of calves. These results correspond quite well with the literature. Harbers et al., (2000) also found a slight negative genetic correlation $(-0.07)$ between direct and maternal effects for stillbirth in first-parity Holsteins. Manfredi et al., (1991) estimated the genetic correlation between direct and maternal effects for calving difficulty to -0.1 , while Ducrocq (2000) obtained a genetic correlation of 0 between direct and maternal effects for calving difficulty in Holsteins in all parities. The change in sign and in the correlation between direct and maternal effects for calving difficulty and stillbirth when adjusting for calving difficulty at second calving are most probably due to the uncertainness of these estimates (the heritabilities and incidences are very low).
The genetic correlations between stillbirth and calving difficulty in first-calvers were rather high $(0.78$ and 0.84 ), and in the range of what was found in the review by Meijering (1984). In a more recent study in Britain, a lower correlation, 0.40 , was found between the two traits when all parities were included (McGuirk et al., 1999). The results emphasize the importance of including both traits in the genetic evaluation of bulls.

\section{Season and Age}

The variation in results of stillbirth and calving difficulty over seasons was less than quite small in our study, differing 4\%-units between lowest and highest rate of calving difficulty and only $2 \%$-units for stillbirth rate (Figure 2). By comparison, the fluctuation over the year, e.g. in McGuirk et al., (1999), was 7.5\%-units in calving difficulty. In earlier reviews by Meijering (1984) and McGuirk et al., (1999), the highest rates evidently occur in late autumn and winter, whereas we found the highest rate of calving difficulty in spring and almost no difference in stillbirth rate from October to July. The low rates of calving difficulty in summer and early autumn in our study might be attributable to less intense supervision of the calving while out at pasture, and that during that period heifers are in good physical condition.

The age of the heifer at calving is an important factor to take into account, from a management point of view. Our results suggest that it is essential not to let the heifers conceive too early. Calving difficulty rates were rather high up to about 30 mo of age, when giving birth to a bull calf. The difference between bull and heifer calves in our study was probably an effect of bull calves being heavier than heifer calves.

\section{CONCLUSIONS}

From this study it can be concluded that the genetic variation in both stillbirth rate and calving difficulty at first calving is substantial in the Holstein breed whether measured as direct or as maternal traits. In second-calvers, however, the corresponding genetic variation is small. Therefore it is important to use the records from first calving for routine evaluation of bulls regarding calving traits and to use records from bulls 
as both sires and maternal grandsires. About half of all stillborn calves were born without causing calving difficulty, so genetic evaluation of bulls for both calving traits is essential. It is also important to allow a moderate age at first calving to avoid increasing the rates of stillbirth and calving difficulty.

\section{ACKNOWLEDGMENTS}

The Swedish Farmers' Foundation for Agricultural Research (SLF) and the AGRIA Insurance Company are acknowledged for financial grants. We are also grateful to the Swedish Dairy Association for providing the data.

\section{REFERENCES}

Berglund, B. 1996. Ongoing research on the causes of variation in calving performance and stillbirths in Swedish dairy cattle. Interbull Bull. 12:78-83.

Berglund, B., and J. Philipsson. 1992. Increasing stillbirth rate in the Swedish Friesian population. 43rd Ann. Mtg. EAAP. 1992. Madrid, Spain.

Calo, L. L., R. E McDowell, L. D. VanVleck, and P. D. Miller. 1973. Genetic aspects of beef production among Holstein-Friesians pedigree selected for milk production. J. Anim. Sci. 37:676-682.

Dempster, E. R., and I. M. Lerner. 1950. Heritability of threshold characters. Genetics 35, 212-236.

Ducrocq, V. 2000. Calving ease evaluation of French dairy bulls with a heteroskedastic threshold model. 51st Ann. Mtg. EAAP. Paper G 4.2. The Hague, The Netherlands.

Harbers, A., L. Segeren, and G. de Jong. 2000. Genetic parameters for stillbirth in The Netherlands. Interbull Bull. 25:117-122.

Jensen, J., and P. Madsen. 1994. DMU: A package for the analysis of multivariate mixed models. Pages 45-46 in Computing strategies and software 22. Proc. 5th World Congr. Genet. Appl. Livest. Prod. Guelph, Canada.
Jensen, J., E. A. Mäntysaari, P. Madsen, and R. Thompson. 1997. Residual maximum likelihood estimation of (co)variance components in multivariate mixed linear models using average information. J. Ind. Soc. Agric. Stat. 49:215-236.

Jensen, J. 1994. Bayesian analysis of bivariate mixed models with one continuous and one binary trait using the Gibbs sampler. Pages 333-336 in Proc. 5th World Congr. Genet. Appl. Livest. Prod. Guelph, Canada.

Kriese, L. A., J. K. Bertrand, and L. L. Benyshek. 1991. Age adjustment factors, heritabilities and genetic correlations for scrotal circumference and related growth traits in Hereford and Brangus bulls. J. Anim. Sci. 69:478-489.

Manfredi, E., V. Ducrocq, and J. L. Foulley. 1991. Genetic analysis of dystocia in dairy cattle. J. Dairy Sci. 74:1715-1723.

McGuirk, B. J., I. Going, and A. R. Guilmour. 1999. The genetic evaluation of UK Holstein Friesian sires for calving ease and related traits. Anim. Sci. 68:413-422.

Meijering, A. 1984. Dystocia and stillbirths in cattle-A review of causes, relations and implications. Livest. Prod. Sci. 11:143-176.

Meyer, C. L., P. J .Berger, K. J. Koehler, J. R. Thompson, and C. G. Sattler. 2000. Interactions among factors affecting stillbirths in Holstein Cattle in the United States. J. Dairy Sci. 83:2657-2663.

Meyer, C. L., P. J .Berger, K. J. Koehler, J. R. Thompson, and C. G. Sattler. 2001. Phenotypic trends in incidence of stillbirths for Holsteins in the United States. J. Dairy Sci. 84:515-523.

Philipsson, J. 1976a. Studies on calving difficulty, stillbirth and associated factors in Swedish cattle breeds. I. General introduction and breed averages. Acta Agric. Scand. 26:151-164.

Philipsson, J. 1976b. Studies on calving difficulty, stillbirth and associated factors in Swedish cattle breeds. III. Genetic parameters. Acta Agric. Scand. 26:211-220.

Philipsson, J., L. Steinbock and B. Berglund. 1997. Considering stillbirths in the breeding program? Interbull Bull. 18:25-27.

Sorensen, D. 1996. Gibbs sampling in quantitative genetics. Internal Report No. 82. Page 165 in Danish Inst. Anim. Sci., Tjele. Denmark.

Sorensen, D., S. Andersen, D. Gianola, and I. Korsgaard. 1995. Bayesian interference in threshold models using Gibbs sampling. Genet. Sel. Evol. 27:229-249.

Steinbock, L., P. Gates, B. Berglund, and J. Philipsson. 1997. Direct and maternal genetic effects on stillbirths at different parities in Swedish Holsteins. 48th Annual Mtg. EAAP. Vienna, Austria. Paper G. 3.17.

Swedish Dairy Association. 2000. Annual statistics 1998-1999. 